\title{
National Smile Month launches in its fifth decade
}

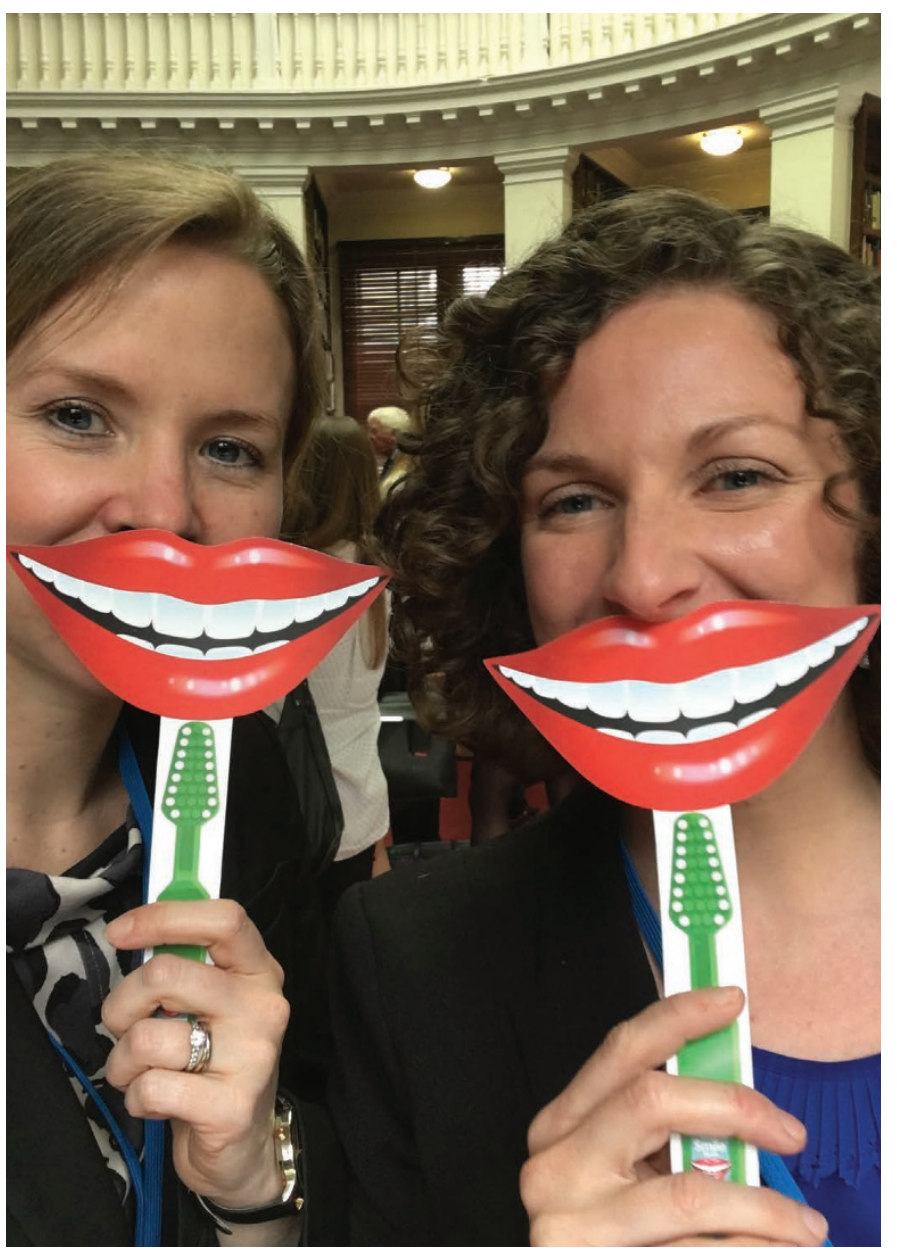

BDJ News Editor Kate Quinlan (left) and Senior Managing Editor Ruth Doherty at the launch of National Smile Month 2017

\section{On 9 May 2017 the 41st National Smile Month was officially} launched at Sixty One Whitehall, an historic building in Westminster. Organisers the Oral Health Foundation are calling for National Smile Month 2017 to be an opportunity for health professionals to bring their communities together and be inspired to spread positive oral health messages nationwide.

Dr Nigel Carter OBE, CEO of the Oral Health Foundation, said: 'Taking part in National Smile Month is so easy. It doesn't necessarily involve lots of time or money, just the passion to make a difference and help promote oral health in your community. Whether it's in your dental practice, hospital or general practice, school, pharmacy, retail outlet, workplace or even out on the streets themselves, use the campaign to educate people about the importance of good oral health

'Our ultimate goal is to improve the oral health of every person in the UK and enable them to smile with confidence. This is a huge task that we need your help to achieve. We are looking for people who can take our values and desire for oral health education and come up with fun and engaging ways to spread the word among their community.'

The campaign helps deliver the Oral Health Foundation's three key messages as a pathway to good oral health:

- Brush your teeth last thing at night and at least one other time during the day, with a fluoride toothpaste

- Cut down on how often you have sugary foods and drinks

- Visit the dentist regularly - as often as they recommend.

Suggested National Smile Month events include a Smileathon, a Two Minute toothbrushing Challenge, school visits, a communal Brushathon, and fundraising such as a sponsored dance, race or face painting.

For more inspiration on how to get involved in National Smile Month 2017, which runs from 15 May to 15 June, visit www.smilemonth.org/events.

\section{BOOK REVIEW}

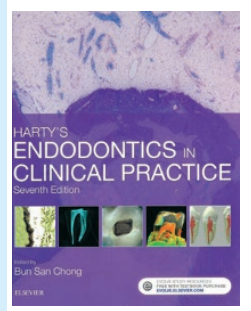

\section{HARTY'S ENDODONTICS IN CLINICAL PRACTICE,SEVENTH EDITION}

Bun San Chong

Elsevier, 2016

price $f 51.99$ pp 352

ISBN: 9780702058356

Every day in clinical practice we are faced with patients presenting with conditions and diseases of the dental pulp and periapical tissues. This book provides a clear and concise explanation of the diagnosis and clinical management of such conditions.

This new edition serves as an up-to date, evidence-based comprehensive endodontic clinical guide and provides the audience with an update of current endodontic developments.

The topic areas are arranged in a logical and practical order beginning with an introduction to endodontics and evidence-based practice, diagnosis, anatomy, management of pulpal conditions through to clinical non-surgical and surgical endodontic management and restoration of endodontically treated teeth. Other topics also include pain management, endodontics in primary teeth and endodontic aspects of traumatic injuries but this list is not exhaustive. Thus, the text provides an overall well-rounded insight into the principles of endodontics. There is also equal emphasis on the clinical aspects of endodontics which is helpful to the clinician in a practical sense.

The book is enriched with newly published colour photos, illustrations and radiographs, which help engage the audience and make for easier reading. Its small size makes it a practical and user-friendly text while providing relevant references for further reading at the end of each topic. The book also serves as an excellent learning tool. Incorporated into each topic are learning outcomes and summary boxes. The seventh edition also comes with access to an online selfassessment resource comprising of clinical cases with images and a bank of MCQs to reinforce and aid the learning process.

This book is a highly useful resource for the undergraduate, those who are pursuing postgraduate studies in endodontics, those with an interest in endodontics and for the general practitioner alike.

S. Mehta 